\title{
PENGARUH BIAYA PAKAN DAN TENAGA KERJA TERHADAP KEUNTUNGAN USAHA AYAM RAS PETELUR MILIK VONY KANAGA DI KELURAHAN TAWAAN KOTA BITUNG (Study kasus)
}

\author{
Brian Tumion, V.V.J. Panalewen", A. Makalew, B. Rorimpandey \\ Fakultas Peternakan Universitas Sam Ratulangi Manado, 95115
}

\begin{abstract}
ABSTRAK
Penelitian ini dilaksanakan pada usaha ayam ras petelur milik Vony Kanaga di Kecamatan Ranowulu Kota Bitung. masalah penelitian ini yaitu berapa besar pengaruh biaya pakan dan tenaga kerja terhadap keuntungan dan berapa besar keuntungan yang diperoleh perusahaan peternakan ayam ras petelur di Kecamatan Ranowulu Kota Bitung. Tujuan penelitian ini yaitu untuk mengetahui pengaruh biaya pakan dan tenaga kerja terhadap keuntungan perusahaan peternakan ayam ras petelur, dan untuk mengetahui keuntungan yang diperoleh perusahaan peternakan ayam ras petelur di Kecamatan Ranowulu Kota Bitung. Metode pengambilan data yang digunakan ialah metode survey. Data yang diambil adalah data primer dan sekunder. Kecamatan Ranowulu Kota Bitung di tentukan berdasarkan populasi terbanyak yang ada di Kota Bitung. Model analisis data yaitu analisis regresi linier berganda dan analisis keuntungan. Variabel yang diukur yaitu biaya pakan, biaya tenaga kerja dan keuntungan. Hasil penelitian diperoleh bahwa rata-rata biaya pakan ayam ras petelur per hari yaitu Rp. 7.813.410. Ratarata biaya tenaga kerja per hari yaitu Rp. 2.388.000. Total Penerimaan dari hasil penjualan telur dan feses diperusahaan ayam ras petelur milik Vony Kanaga sebesar Rp. 13.514.520 sehingga dapat diperoleh
\end{abstract}

*Korespondensi (Corresponding Author)

Email: vicky panelewen@yahoo.com keuntungan sebesar Rp. 3.313.110.

Berdasarkan hasil penelitian dapat disimpulkan bahwa biaya pakan dan tenaga kerja secara simultan berpengaruh sangat nyata terhadap keuntungan dan secara parsial biaya pakan berpengaruh sangat nyata sedangkan biaya tenaga kerja berpengaru tidak nyata terhadap keuntungan pada perusahaan peternakan ayam ras petelur milik Vony Kanaga di Kecamatan Ranowulu Kota Bitung. Keuntungan yang diperoleh perusahaan peternakan ayam ras petelur di kecamatan Ranowulu Kota Bitung sebesar Rp. 3.313.110 per hari.

Kata Kunci : Biaya pakan. Biaya Tenaga Kerja, Keuntungan

\section{ABSTRACT}

EFFECT OF FEED AND OPERATING COSTS ON PROFIT OF CHICKEN LAYING FARM OWNED BY VONY KANAGA AT TAWAAN VILLAGE IN BITUNG CITY (Case study). This research was conducted in Vony Kanaga laying farm located in District Ranowulu Bitung City. The research problem was how the influence of feed and labor costs to the amount of profits and how much profit can be obtained at the company laying chicken farm in the district of Bitung City Ranowulu. The purpose of this study is to determine the effect of feed and labor costs against profits in laying chicken company, to find out the 
benefits of the company laying chicken farm in the district of Bitung City Ranowulu. The data collection method is using a field survey using primary and secondary data. Subdistrict Ranowulu Bitung determined based on the largest population in the city of Bitung. Model analysis of data that multiple linear regression analysis and profit. The measured variable is the cost of feed, labor costs and profits. The result showed that the average cost of laying chicken feed per day is Rp. 7.813.410. The average labor cost per day is Rp. 2.388.000. Total Proceeds from the sale of eggs and feces in the companyowned chicken laying Vony Kanaga Rp. 13.514.520 so as to obtain profit of $\mathrm{Rp}$. 3.313.110. Based on the results of this study concluded that the cost of feed and labor simultaneously significant effect on profits in the company-owned farm chicken laying Vony Kanaga in District Ranowulu Bitung City. Company-owned farm chicken laying Vony Kanaga in District Ranowulu gives an average profit of Rp. 3.313.110

Keywords: Feed Cost, Labor Cost, Profit

\section{PENDAHULUAN}

Pembangunan peternakan merupakan salah satu aspek penting dalam pembangunan pertanian, terutama disaat adanya krisis ekonomi dan moneter sehingga peranan petani peternak sangat menentukan kerberhasilan pembangunan tersebut. Program pembangunan peternakan merupakan rangkaian upaya untuk memfasilitasi, melayani dan mendorong berkembangnya sistem agribisnis yang berdaya saing, berkerakyatan, dan berkelanjutan untuk meningkatkan kesejahteraan masyarakat.

Pembangunan subsktor peternakan berperan meningkatkan kualitas sumber daya manusia secara berkelanjutan melalui perbaikan gizi, peningkatan pendapatan, mensejahterakan masyarakat dan peternak serta membuka kesempatan kerja bagi masyarakat (Simarmata, dkk 2008). Tantangan utama yang dihadapi adalah bagaimana menghasilkan produk peternakan yang berdaya saing tinggi baik dalam aspek kuantitas maupun kualitas produk yang dihasilkan, kontinuitas, pelayanan dan harga. Pembangunan subsektor peternakan bertujuan untuk menyediakan pangan hewani berupa daging, susu, serta telur yang bernilai gizi tinggi, meningkatkan pendapatan peternak, meningkatkan devisa dan memperluas kesempatan kerja. Peningkatan dalam subsektor peternakan akan berdampak positif bagi masyarakat dan juga bagi perusahaan peternakan.

Prospek usaha peternakan ayam ras petelur dinilai sangat baik dilihat dari pasar dalam negeri maupun luar negeri. Jika ditinjau dari aspek penawaran dan permintaan, maka aspek penawaran ayam ras petelur masih belum mencapai kapasitas produksi yang sesungguhnya sedangkan dari aspek permintaan produksi telur ayam ras 
petelur baru mencukupi kebutuhan pasar dalam negeri sebesar $65 \%$ sisanya dipenuhi dari telur ayam kampung, itik, dan puyuh (Mappigau dan Esso 2011). Produksi dan pengembangan ayam petelur diharapkan mampu mencukupi pemenuhan produksi dalam negeri dan memperoleh keuntungan yang multi fungsi dari unit usaha, antara lain dapat mengoptimalkan jam kerja peternak dan dapat mengatasi masalah pengangguran dalam negeri (Parasdya, dkk 2013).

Tantangan dan hambatan dalam usaha peternakan ayam ras petelur antara lain manajemen pemeliharaan yang lemah, fluktuasi harga produk, fluktuasi harga sarana produksi, marjin usaha rendah, sarana produksi yang sangat tergantung pada impor dan persaingan global yang semakin ketat (Susanto, dkk 2015).

Menanggapi permasalahan diatas maka rumusan masalah penelitian ini yaitu bagaimana pengaruh biaya pakan dan tenaga kerja terhadap besarnya keuntungan dan berapa besar keuntungan yang diperoleh pada perusahaan peternakan ayam ras petelur di Kecamatan Ranowulu Kota Bitung. Tujuan penelitian ini yaitu untuk mengetahui pengaruh biaya pakan dan tenaga kerja terhadap keuntungan pada perusahaan peternakan ayam ras petelur dan untuk mengetahui keuntungan yang diperoleh perusahaan ayam ras petelur di Kecamatan Ranowulu Kota Bitung.

\section{METODE PENELITIAN}

Penelitian ini dilaksanakan pada perusahaan peternakan ayam ras petelur milik Vony Kanaga di Kecamatan Ranowulu Kota bitung mulai bulan November sampai bulan Desember Tahun 2016.

Penelitian ini dilakukan dengan metode studi kasus. Menurut Arikunto (2006), studi Kasus adalah suatu penelitian yang dilakukan secara intensif, terperinci dan mendalam yang dilakukan terhadap suatu organisasi atau lembaga tertentu, baik secara individu maupun kelompok. Metode pengambilan data yang digunakan ialah metode survey pada satu perusahaan peternakan ayam ras petelur di Kecamatan Ranowulu Kota Bitung. Data yang diambil terdiri dari data primer dan sekunder. Data primer yaitu data yang berasal dari sumber asli atau responden dan diperoleh melalui wawancara dengan menggunakan daftar kuesioner dan pengamatan langsung di perusahaan peternakan ayam ras petelur milik Vony Kanaga di Kecamatan Ranowulu Kota Bitung, data sekunder yaitu data yang diperoleh melalui kantor Kelurahan Tewaan, kantor Kecamatan 
Ranowulu Kota Bitung dan data dari Badan Pusat Statistik Manado.

Model analisis data yang digunakan dalam penelitian ini yaitu analisis regresi linier berganda dan analisis keuntungan. Analisis regresi linier berganda digunakan untuk mengukur pengaruh variabel independen (biaya pakan dan tenaga kerja) terhadap variabel dependen (keuntungan). Model analisis regresi linier berganda yaitu $\left(\mathrm{Y}=\mathrm{a}+\mathrm{b}_{1} \mathrm{X}_{1}+\mathrm{b}_{2} \mathrm{X}_{2}\right)$ dengan keterangan sebagai berikut

Keterangan :

$$
\begin{array}{ll}
\mathrm{Y} & =\text { Keuntungan } \\
\mathrm{a} & =\text { Konstanta } \\
\mathrm{b} 1, \mathrm{~b} 2 & =\text { Koefisien Regresi } \\
\mathrm{X} 1 & =\text { Biaya Pakan } \\
\mathrm{X} 2 & =\text { Biaya Tenaga Kerja }
\end{array}
$$

Untuk menguji apakah biaya pakan dan tenaga kerja secara simultan berpengaruh nyata terhadap keuntungan digunakan uji F.

Untuk menguji apakah biaya pakan dan tenaga kerja secara parsial berpengaruh nyata terhadap keuntungan digunakan uji $\mathrm{t}$.

Analisis keuntungan digunakan untuk mengetahui berapa besar keuntungan yang diperoleh perusahaan peternakan ayam ras petelur milik Vony Kanaga di Kecamatan Ranowulu Kota Bitung. Menurut Hanafie (2010), keuntungan adalah selisih antara total revenue (TR) dan total cost (TC) secara matematis dapat dituliskan sebagai berikut : $\quad \Pi=\mathrm{TR}-\mathrm{TC}$

Keterangan : $\Pi=$ Keuntungan

TR = Total Revenue (Penerimaan Total)

TC = Total Cost (Biaya Total)

\section{HASIL DAN PEMBAHASAN}

\section{Deskripsi Perusahaan Penelitian}

Perusahaan Vony Kanaga bertempat di Kota Bitung Kecamatan Ranowulu Kelurahan Tewaan. Kecamatan Ranowulu terletak dibagian Utara Kota Bitung dengan luas Kecamatan 157,56 ha atau 50,26\% dari luas Kota Bitung dan mempunyai batasbatas wilayah sebagai berikut:

- Utara : Kabupaten Minut \& Laut Maluku

- Selatan : Kec Matuari dan Kec Girian

- Timur : Kecamatan Aertembaga

- Barat : Kabupaten Minut

Kecamatan Ranowulu merupakan Kecamatan yang memiliki wilayah paling luas di Kota Bitung dan memiliki 11 Kelurahan. Kecamatan Ranowulu mempunyai dua perusahaan peternakan ayam ras petelur dengan populasi ternak yaitu ; 37.000 ekor (BPS Kota Manado, 2015).

Perusahaan peternakan ini didirikan oleh bapak Yohanis Kanaga pada tahun 
1994. Pada tahun 2009 perusahaan ini di wariskan pada anaknya yaitu Vony Kanaga. Perusahaan ini dibangun di atas lahan dengan luas sebesar 1,5 Ha, dengan jumlah ternak 20.000 ekor ayam ras petelur. Tenaga kerja dalam pengelolaan peternakan Vony Kanaga berjumlah 40 orang yang kesemuanya memiliki tugas dan tanggung jawab masing-masing. Pendistribusian hasil produksi telur perusahaan melalui dua cara yaitu dengan menggunakan cara produksi telur diambil langsung oleh konsumen dan melalui pemesanan lewat telephone untuk langganan.

\section{Analisis Biaya Pakan dan Tenaga Kerja}

Biaya dari usaha ternak ayam ras petelur terdiri dari biaya pakan dan biaya tenaga kerja. Hasil penelitian menunjukkan bahwa rataan biaya pakan dan tenaga kerja sebesar Rp. 10.201.410 per hari. Biaya pakan merupakan biaya produksi terbesar dengan persentase sebesar 77 persen dari total biaya produksi. Rataan biaya pakan untuk ternak ayam ras petelur sebesar Rp. 7.813.410 seperti yang disajikan pada Tabel 1.

Berdasarkan hasil penelitian di perusahaan ayam ras petelur diperoleh rataan konsumsi pakan ayam ras petelur sebanyak 109 gram per ekor per hari. Hal ini sejalan dengan pendapat Anggorodi (1985) bahwa konsumsi pakan untuk ayam ras petelur yang sedang berproduksi berkisar 100-125 gram/ekor/hari. Konsumsi pakan ternak ayam ras petelur di perusahaan meningkat sesuai umur, hal ini sejalan dengan penelitian Marginingtyas, dkk (2015), Pemberian nutrisi kepada ayam ras petelur tidak sama antara satu dengan yang lainnya karena kadar nutrisi yang diberikan dipengaruhi oleh umur ayam. Bahan pakan yang digunakan yaitu jagung, dedak, tepung ikan, grit dan konsentrat. Bahan pakan kemudian dicampur menggunakan mixer.

Perusahaan ini memiliki 40 tenaga kerja dengan tugas dan tanggung jawab masing-masing. Berdasarkan hasil penelitian jumlah jam kerja setiap tenaga kerja sebanyak 7 jam perhari diluar jam istirahat. Gaji yang diterima oleh tenaga kerja yaitu perbulan sebesar Rp. 1.800.000 per orang. Rataan biaya tenaga kerja dihitung berdasarkan upah yang berlaku diperusahaan peternakan ayam ras petelur sebesar Rp. 2.388.000 untuk 40 orang per hari (Tabel 1).

\section{Analisis Penerimaan dan Keuntungan}

Penerimaan dari usaha ternak ayam ras petelur adalah hasil penjualan telur dan feses, sedangkan keuntungan diperoleh dari total penerimaan dikurangi biaya yang dikeluarkan yaitu biaya pakan dan tenaga kerja. Hasil penelitian menunjukkan 
produksi telur pada setiap harinya mengalami peningkatan. Produksi telur yang baik harus disesuaikan dengan kualitas dan kuantitas pakan, hal ini sejalan dengan Tugiyanti dan Iriyanti (2012) yang menyatakan bahwa produksi dan kualitas telur akan maksimal apabila kualitas pakan yang diberikan dapat memenuhi kebutuhan berdasarkan umur dan tatalaksana pemeliharaan. Rata-rata produksi telur per hari 10.845 butir dengan hen day productions 54\%. Harga telur dalam perusahaan ini sebesar Rp.1200 per butir sehingga penerimaan dari hasil penjualan telur sebesar Rp. 13.014.520. Feses yang dihasilkan ternak ayam ras petelur /ekor/hari sebanyak 150 gram sehingga jumlah feses untuk 20000 ekor ternak ayam ras petelur sebanyak $3000 \mathrm{Kg}$. Feses yang dijual dimasukan kedalam sak dengan berat per sak $30 \mathrm{~kg}$. Feses yang dihasilkan perhari mencapai 100 sak dengan harga Rp. 5000 per sak sehingga rata rata penerimaan dari hasil penjualan feses sebesar Rp. 500.000. Total penerimaan yaitu Rp. 13.514.520 lebih besar dari total biaya pakan dan tenaga kerja yaitu Rp. 10.201.410 dapat dilihat pada Tabel 2.

Berdasarkan Tabel 2. keuntungan per hari perusahaan ayam ras petelur milik Vony Kanaga sebesar Rp.3.313.110.
Keuntungan diperoleh dari selisih antara total penerimaan dengan total pengeluaran, hal ini sesuai dengan pendapat Asnawi (2009) bahwa keuntungan pada usaha peternakan ayam ras petelur merupakan selisih antara penerimaan total dengan biaya total produksi yang dikeluarkan.

\section{Analisis Biaya Pakan dan Tenaga Kerja Terhadap Keuntungan di Perusahaan Vony Kanaga Kecamatan Ranowulu Kota Bitung}

Hasil analisis data menggunakan regresi linier berganda diperoleh persamaan sebagai berikut :

$Y=-8539933.965 a+1.593 X_{1}-250 X_{2}$

Hasil analisis regresi diperoleh koefisien regresi $\mathrm{X}_{1}$ (biaya pakan) sebesar 1.593 . Artinya apabila $\mathrm{X}_{1}$ (biaya pakan) naik Rp.1 maka Y (keuntungan) akan naik sebesar Rp. 1.593. Menurut pendapat Soekartawi (1990), bahwa semakin tinggi biaya yang dikeluarkan maka akan mengurangi besarnya keuntungan. Berbeda dengan hasil penelitian ini naiknya biaya pakan masih meningkatkan keuntungan. Hal ini karena komposisi bahan baku pakan telah dimodivikasi oleh perusahaan sehingga biaya pakan yang dikeluarkan relative kecil dan harga pakan yang juga murah yaitu Rp. $3.500 / \mathrm{kg}$. 
Tabel 1. Biaya Variabel Usaha Ayam Ras Petelur

\begin{tabular}{clcc}
\hline No & Jenis Biaya & $\begin{array}{c}\text { Jumlah Rata-rata } \\
(\text { Rp/Hari })\end{array}$ & Persentase (\%) \\
\hline 1. & Biaya Pakan & 7.813 .410 & 77 \\
2. & Biaya Tenaga Kerja & 2.388 .000 & 23 \\
\hline & Total & $\mathbf{1 0 . 2 0 1 . 4 1 0}$ & $\mathbf{1 0 0}$ \\
\hline
\end{tabular}

Tabel 2. Keuntungan Usaha ayam ras petelur di Perusahaan Vony Kanaga Perhari

\begin{tabular}{llll}
\hline No & Uraian & $\begin{array}{l}\text { Rata-rata } \\
\text { (Rp/Hari) }\end{array}$ & Persentase (\%) \\
\hline $\mathbf{1 .}$ & Penerimaan : & \\
& a. Hasil Penjualan telur & 13.014 .520 & 96 \\
& b. Hasil Penjualan Feses & 500.000 & 4 \\
\hline & Total penerimaan (a+b) & 13.514 .520 & 100 \\
\hline $\mathbf{2 .}$ & Pengeluaran : & 77 \\
& a. Biaya Pakan & 7.813 .410 & 23 \\
\hline & b. Tenaga kerja & 2.388 .000 & 100 \\
\hline 3. & Total Pengeluaran (a+b) & 10.201 .410 & \\
\hline
\end{tabular}

Koefisien regresi untuk $\mathrm{X}_{2}$ (biaya tenaga kerja) sebesar -250 artinya apabila $\mathrm{X}_{2}$ (biaya tenaga kerja) naik Rp.1 maka akan mengakibatan penurunan Y (keuntungan) sebesar Rp. 250. Hasil ini sejalan dengan teori semakin besar biaya produksi yang dikeluarkan maka keuntungan akan semakin kecil. hasil ini juga sejalan dengan penelitian Dewanti dan Sihombing (2012), yang memperoleh hasil koefisien regresi untuk tenaga kerja $-0,015$ hal ini karena tenaga kerja yang digunakan dalam penelitian sebagian besar berasal dari luar keluarga, apabila terjadi penambahan tenaga kerja dalam perusahaan maka akan mengakibatkan terjadinya penurunan keuntungan.

Koefisien korelasi berganda (Multiple $R$ ) merupakan nilai keeratan hubungan antara seluruh variable independen dengan variable dependen. Koefisien korelasi berganda dalam penelitian ini sebesar 0.670 menunjukan hubungan yang cukup erat antara variable independen $X_{1}$ (biaya pakan) dan $X_{2}$ (tenaga kerja) dengan variable dependen $\mathrm{Y}$ (keuntungan) yaitu sebesar $67 \%$. 
Untuk mengetahui variasi naik turunnya keuntungan dapat dilihat pada nilai koefisien determinasi $\mathrm{R}^{2}$ ( $\mathrm{R}$ square) sebesar 0,693. Nilai ini menunjukan bahwa variasi naik turunnya keuntungan dipengaruhi oleh variable $X_{1}$ dan $X_{2}$ sebesar $69,3 \%$ sedangkan 30,7 \% dipengaruhi oleh faktor lain yang tidak termasuk dalam analisis ini.

Berdasarkan hasil pengujian dengan menggunakan uji F (lampiran 4), menunjukan bahwa secara simultan biaya pakan dan tenaga kerja berpengaruh sangat nyata terhadap keuntungan $(\alpha=0.000)$.

Secara parsial, pengujian pengaruh biaya pakan dan tenaga kerja menggunakan uji T (lampiran 4), biaya pakan berpengaruh sangat nyata $(\alpha=0.000)$ sedangkan biaya tenaga kerja berpengaruh tidak nyata terhadap keuntungan $(\alpha=0.907)$.

\section{KESIMPULAN}

1. Biaya pakan dan tenaga kerja secara simultan berpengaruh sangat nyata terhadap keuntungan pada perusahaan peternakan ayam ras petelur di Kecamatan Ranowulu Kota Bitung.

2. Secara parsial biaya pakan berpengaruh sangat nyata sedangkan biaya tenaga kerja berpengaruh tidak nyata terhadap keuntungan
3. Keuntungan yang diperoleh perusahaan peternakan ayam ras petelur di Kecamatan Ranowulu Kota Bitung sebesar Rp. 3.313.110 per hari.

\section{DAFTAR PUSTAKA}

Aggorodi. 1985. Kemajuan Mutakhir Dalam Ilmu Makanan Ternak Unggas. Universitas Indonesia. Jakarta.

Arikunto, S. 2006. Prosedur Penelitian Suatu Pendekatan Praktik (Jakarta : Rineka Cipta). hal. 142.

Asnawi, A. 2009. Perbedaan Tingkat Keuntungan Usaha Peternakan Ayam Ras Petelur Antara Sebelum Dan Sesudah Memperoleh Kredit PT. BRI Di Kabupaten Pinrang. Jurnal Buletin Ilmu Peternakan Dan Perikanan, 13(1) : 1-14

Badan Pusat Statistik. 2015. Bitung City in Figures. Manado. Katalog BPS: 1102001.7172 .

Dewanti, R dan G. Sihombing. 2012. Analisis Pendapatan Ayam Ras (Studi Kasus di Kecamatan Tegalombo, Kabupaten Pacitan). Jurnal Buletin Peternakan Universitas Sebelas Maret, 36(1): 48-56

Hanafie, R. 2010. Pengantar Ekonomi Pertanian. Edisi 1/Pertama. Penerbit Andi. Yogyakarta

Marginingtyas, E., W.F. Muhmudy dan Indriati. 2015. Penentuan Komposisi Pakan Ternak Untuk Memenuhi Kebutuhan Nutrisi Ayam Petelur dengan Biaya Minimum Menggunakan Algoritma Genetika. 
Jurnal Mahasiswa PTIIK. Universitas Brawijaya. 5( 12) : 1-7

Mappigau, P dan A.Esso. 2011. Analisis Strategi Pemasaran Telur Pada Peternakan Ayam Ras Skala Besar Di Kabupaten Sidrap. Fakultas Peternakan. Universitas Hasanuddin. Jurnal Agribisnis, 10 (3): 14-31

Parasdya, W., S. Mastuti dan O.D. Djatmiko. 2013. Analisis Finansial Usaha Peternakan Ayam Petelur di Kecamatan Kademangan Distric of Blitar. Jurnal Ilmiah Peternakan, 1(1) : 88-98.

Simarmata, H. Hardinsyah dan D.K. Pranadji. 2008. Analisis Kebijakan dan Program Subsektor Peternakan Kabupaten Lampung Barat. Jurnal Gizi dan Pangan, 3(3) :139 - 143
Soekartawi. 1990. Teori Ekonomi Produksi Dengan Pokok Bahasan CobbDouglas. CV. Rajawali Jakarta.

Susanto,E.,G.A.Raharja dan A. Muhammad. 2015. Analisis Faktor-Faktor Yang Mempengaruhi Minat Konsumen Terhadap Pembelian Telur Ayam Ras Di Pasar Wilayah Kecamatan Babat Kabupaten Lamongan. Program Studi Peternakan. Fakultas Peternakan. Universitas Islam Lamongan. Jurnal Ternak, 6 (1) : 121

Tugiyanti E dan N.Iriyanti. 2012. Kualitas Eksternal Telur Ayam Petelur Yang Mendapat Ransum Dengan Penambahan Tepung Ikan Fermentasi Menggunakan Isolat Produser Antihistamin. Jurnal Aplikasi Teknologi Pangan, 1(2) : 44 $-47$ 